American Journal of Primatology 55:25-42 (2001)

\title{
Rank and Grooming Reciprocity Among Females in a Mixed-Sex Group of Captive Hamadryas Baboons
}

IRIS LEINFELDER ${ }^{1 *}$, HAN DE VRIES $^{2}$, REBEKKA DELEU $^{1}$, AND MARK NELISSEN ${ }^{1}$

${ }^{1}$ University of Antwerp, RUCA, Behavioural Biology, Antwerp, Belgium

${ }^{2}$ Ethology and Socioecology Group, Utrecht University, Utrecht, The Netherlands

In a mixed-sex, captive group of hamadryas baboons (Papio hamadryas hamadryas) we investigated whether female grooming relationships are affected by their dominance ranks. Seyfarth's [1977] grooming for support model and Barrett et al.'s [1999] biological market model both predict that in primate groups where competition for monopolizable resources is high, grooming among females is based, at least partly, on the interchange of grooming for rank-related benefits, and that rank thus influences the distribution of grooming in females. Contrary to this prediction, our results show that despite the existence of a linear dominance hierarchy, rather strict dominance relationships, and high food-related aggression rates, grooming among female hamadryas baboons is not affected by rank and is only exchanged for itself. This is understandable since rank differences in our study group only result in differential access to limited, preferred food items that are not actively shared. Although some females are more likely to tolerate one another at the food pile, this tolerance is not determined by their grooming efforts and interchange of grooming for rank-related benefits does not occur. We conclude that female hamadryas baboons groom others in order to be groomed by them, which is supported by our observation that grooming reciprocity within a dyad increases when more grooming occurs in this dyad. Our results indicate that grooming is indeed a valuable commodity in itself, probably because of its stress- and tension-reducing effect. Based on our findings, the existing groom trade model is extended to include circumstances in which monopolizable resources are available but are not traded for grooming. Am. J. Primatol. 55:25-42, 2001. @ 2001 Wiley-Liss, Inc.

Key words: grooming; baboons; Papio hamadryas hamadryas; dominance; female relationships; biological markets

\section{INTRODUCTION}

Grooming is one of the most common affiliative behaviors among nonhuman primates [Missakian, 1974; Goosen, 1987]. In lemurs and platyrrhine monkeys it seems to serve mainly hygienic purposes, since it tends to be concentrated on

Contract grant sponsor: University of Antwerp and the Royal Zoological Society of Antwerp in association with the University of Antwerp and the Flemish Ministry of Science.

*Correspondence to: Iris Leinfelder; University of Antwerp, Behavioural Biology, Groenenborgerlaan 171, 2020 Antwerp, Belgium. E-mail: irlein@ruca.ua.ac.be

Received 6 June 2000; revision accepted 30 May 2001

(C) 2001 Wiley-Liss, Inc. 


\section{6 / Leinfelder et al.}

those parts of the body that an animal can not reach for itself [Barton, 1985] and grooming time seems to be correlated with body size [Dunbar, 1991]. However, in most catarrhine primates in general, and in baboons, macaques, and chimpanzees in particular, grooming frequencies are much too high to be entirely explained by utilitarian needs. The time devoted to social grooming is correlated with group size instead of body size [Dunbar, 1988, 1991], and in vervets the least often groomed animals do not compensate by high frequencies of autogrooming [Seyfarth, 1980]. Therefore, a variety of not necessarily mutually exclusive social functions have been proposed. These include the establishment and maintenance of social bonds [Carpenter, 1942; Marler, 1965; Kummer, 1968; Dunbar, 1983a; Evans \& Poole, 1984], the restoration of a relationship after an agonistic interaction [de Waal \& van Roosmalen, 1979], and the reduction of tension [Goosen, 1981; Boccia, 1987; Schino et al., 1988; Boccia et al., 1989].

In most matrilineally organized baboon and macaque species grooming is concentrated among maternally-related individuals, and especially within motheroffspring dyads [Sade, 1965, 1972; Missakian, 1974; Kurland, 1977; Altmann, 1980], which form the stable core of the social group [Melnick \& Pearl, 1987]. However, grooming also occurs among nonrelated individuals. Since it is thought to be costly to the actor and beneficial to the recipient, grooming is often considered to be an act of altruism [Kurland, 1977; Seyfarth \& Cheney, 1984, 1988; Cheney \& Seyfarth, 1990]. These altruistic acts can be maintained only if the receiver of the benefit reciprocates to some extent [Trivers, 1971].

Many investigations on the social function of grooming among female primates have been inspired by the grooming for support model introduced by Seyfarth [1977, 1980]. Seyfarth's model is based on the assumption that grooming is interchanged for support in agonistic encounters. According to this model the distribution of grooming interactions is determined by contest competition (direct competition and competitive exclusion) for access to the highest ranking females, since they are valuable as supporters in agonistic interactions. Therefore, this model is sometimes also called the priority of access model. Recently Henzi and Barrett [1999] pointed out that most of the evidence in support of the model is indirect. They noted that the predicted correlation between rank and attractiveness as a grooming partner was confirmed [e.g., Cheney \& Seyfarth, 1990], although the assumed interchange relation between support and grooming was not always present. For example, Fairbanks's [1980] study on vervet monkeys is cited by Cheney and Seyfarth [1990] as evidence for the grooming for support model, although Fairbanks [1980] mentions explicitly that no evidence is found for a causal relation between grooming and subsequent support. Studies on hamadryas baboons by Kummer [1968] and Stammbach [1978] were also cited by Cheney and Seyfarth [1990] as evidence for Seyfarth's grooming model. However, a typical characteristic of female hamadryas baboons is that they do not support one another in agonistic encounters [Kummer, 1990], which indicates that the basic assumption can not be fulfilled.

Partly because of this lack of evidence for Seyfarth's model, and partly because it can only be applied to predict the distribution of grooming interactions when grooming is used in order to obtain future support, Barrett et al. [1999] started to investigate grooming relationships in the context of the recently proposed biological market theory [Noë \& Hammerstein, 1995]. According to this market theory, laws of demand and supply will determine the value of offered commodities and hence the rates at which exchange/interchange will take place. These will be further influenced by the preference for partners offering the highest value, and consequently by contest and outbidding competition within the 
Rank and Grooming in Hamadryas Baboons / 27

trader classes. According to the biological market model proposed by Barrett et al. [1999] it can be predicted that when limited resources can be monopolized, dominant animals will use their exclusive access as a currency for which subordinates try to outbid by increasing their grooming rates (outbidding competition). If dominance relations are relaxed, rank differences will not, or will barely, be reflected in differential access to resources. In this case, grooming will not be interchanged for rank-related benefits and grooming will only be traded for itself. That is, when power differentials are weak, grooming relationships are expected to be highly reciprocal [Barrett et al., 1999; Henzi \& Barrett, 1999, Barrett \& Henzi, 2001]. When grooming is the only commodity to trade, competition for the best groomers will arise and cheaters will be excluded. This would result in good reciprocators preferentially grooming each other [see also Barrett et al., 2000].

Although Barrett et al. [1999] and Henzi and Barrett [1999] are rather skeptical towards Seyfarth's grooming model, since "the assumed link between grooming and coalitionary support is only weakly supported" [Henzi \& Barrett, 1999, p. 49], it is clear that the grooming for support model is itself a particular instance of a biological market. This is suggested also by Noë and Hammerstein [1995], although certain aspects of biological markets, such as the dependency of the relative value of grooming and support on the supply and demand of these commodities, and the possibility of outbidding competition have been left unspecified in the original formulation of the model by Seyfarth.

When the basic assumption (groom to ensure future support) of Seyfarth's original model is replaced by the more general one-that subordinates groom dominants in order to obtain some rank-related commodity in return-both models come to similar predictions for groups in which rank-related access to limited resources (and thus differential resource holding potentials) exists. Seyfarth's model does not include predictions about the distribution of grooming interactions for groups with low differences in resource holding potential. However, with the incorporation of the more general assumption in Seyfarth's model it can be fruitfully applied for groups with relaxed dominance relationships, and extended by the above-mentioned prediction put forward by Henzi and Barrett [1999].

A final logical extension of Seyfarth's model, and also of Barrett et al.'s [1999] model, is the possibility that even though there may be monopolizable resources and a steep dominance rank order (i.e., strong power differentials), no rank-related benefits will be offered in return for grooming. This is the case when the value of the contested resource is too high relative to the value of the grooming offered and at the same time this valuable resource cannot be split up into marketable parts; moreover, the possibility of other services (such as support in agonistic interactions) should also be absent. In this case, the grooming price to buy this indivisible, rank-related commodity would exceed the time available for grooming, and therefore it is to be expected that grooming will only be exchanged for itself.

Another theoretical possibility in which trading of rank-related commodities for grooming would not arise is when the value of grooming is much higher than the value of such a commodity. In this case, the commodity in question is worth competing for; however, it can not compensate for the value of grooming.

Table I presents an overview of the groom trade possibilities, under the main assumption that grooming is a marketable commodity. Six predictions about the distribution of grooming interactions are presented that can be derived from different combinations of factors, including the steepness of the dominance rank order; whether there exist marketable, rank-related commodities; whether these 


\section{8 / Leinfelder et al.}

TABLE I. Groom Trade Model: Six Predictions About the Long-Term Distribution of Grooming Interactions, Assuming That Grooming Is Used as a Marketable Commodity

A. A steep rank order and rank-related, marketable commodities exist. Grooming is (partly) traded for these commodities. Predictions:

1. Attraction to high ranking animals (prediction 1 ):

a. High ranking females are groomed more often than low-ranking ones.

b. Low ranking females groom more often than higher ranking ones.

c. Within a dyad the lower ranking female grooms more often.

2. Due to competition (contest or outbidding) grooming will be mainly taking place among adjacently ranking females (prediction 2 ).

3. Adjacently ranking females groom each other more reciprocally than distantly ranking females (prediction 3).

4. Lower ranking females contribute more to the dyadic grooming rate as rank distance increases (prediction 4).

B. Rank order is not steep, dominance relations are relaxed and there are (almost) no rankrelated commodities. Grooming is (almost) only traded for itself. Predictions:

1. Grooming interactions are highly reciprocal (prediction 5).

2. Reciprocity will be stronger in dyads that groom more (prediction 6 ).

C. Rank order is more or less steep and rank-related commodities exist, but grooming is not traded for these due to value mismatches. There are two possibilities:

1 . The value of a commodity is too high compared with the value of being groomed and the commodity cannot be split up into marketable parts. In this case animals that groom individuals possessing such a valuable commodity, will not receive some of it in return. So grooming will only be traded for itself. See predictions 5 and 6 .

2 . The value of a commodity is too low compared with the value of being groomed. In this case groomers will be more interested in being groomed in return than in obtaining some other low-valued commodity. See predictions 5 and 6.

commodities are divisible; and whether the values of these commodities match with the value of grooming.

The predictions of this groom trade model were tested for the grooming interactions of captive hamadryas females. We observed the grooming interactions among 13 females in a mixed-sex, captive group of hamadryas baboons (Papio hamadryas hamadryas) to investigate whether grooming is used by these baboons as a "currency" that can be interchanged for a rank-related commodity or whether grooming is only exchanged for itself.

\section{METHODS \\ Subjects}

The hamadryas colony at the Antwerp Zoo (Royal Zoological Society Antwerp) was founded in 1977. During the time of the study (1996-1998) it comprised between 26 and 29 individuals. There were two one-male units (OMUs) at the start of this study: Napoleon's OMU contained six adult females, and Witte's unit had three adult females. The subjects of this study were the nine adult and four juvenile female hamadryas baboons (Table II). During the course of this study, all reached sexual maturity. Three of these maturing females were integrated into Witte's OMU, and one became the single female of a third male (Soho) that reached adulthood in the course of the study (Table II).

The animals were housed in an enclosure of about $100 \mathrm{~m}^{2}$ comprising two inside enclosures and a $72 \mathrm{~m}^{2}$ outdoor part surrounded by a ditch. The animals 
Rank and Grooming in Hamadryas Baboons / 29

TABLE II. Female Members of the Hamadryas Baboon Colony at the Antwerp Zoo That Were the Focus of This Study

\begin{tabular}{|c|c|c|c|c|c|c|c|}
\hline & \multicolumn{7}{|c|}{ Dominance rank } \\
\hline & \multicolumn{3}{|c|}{1996} & \multicolumn{2}{|c|}{1997} & \multicolumn{2}{|c|}{1998} \\
\hline & \multicolumn{3}{|c|}{ Whole group Within OMU } & \multicolumn{2}{|c|}{ Whole group Within OMU } & \multicolumn{2}{|c|}{ Whole group Within OMU } \\
\hline \multicolumn{8}{|c|}{ Napoleon's females } \\
\hline Donna & & 2.5 & (1) & 2 & (1) & 1 & (1) \\
\hline Mekka & & 12.5 & (6) & 10.5 & (6) & 10.5 & (6) \\
\hline Muis & & 6 & (3) & 4.5 & (2) & 5 & (2) \\
\hline Piggy & & 5 & (2) & 6.5 & $(3.5)$ & 9 & (5) \\
\hline Pruts & & 9.5 & (5) & 8.5 & (5) & 8 & (4) \\
\hline Tiet & & 7 & (4) & 6.5 & $(3.5)$ & 6.5 & (3) \\
\hline \multicolumn{8}{|c|}{ Witte's females } \\
\hline Flap & & 4 & $(2.5)$ & 4.5 & (3) & 3.5 & (3) \\
\hline Hoofd & & 2.5 & (2.5) & 3 & (2) & 3.5 & (3) \\
\hline Lätta $^{a}$ & & 9.5 & (4) & 8.5 & (4) & 6.5 & (3) \\
\hline Quaza $^{\mathrm{b}}$ & & 9.5 & $\dagger$ & 12 & $\dagger$ & 10.5 & (5.5) \\
\hline Renza $^{\mathrm{b}}$ & & 9.5 & $\dagger$ & 10.5 & (5) & 12.5 & (5.5) \\
\hline Zwart & & 1 & (1) & 1 & (1) & 2 & (1) \\
\hline \multicolumn{8}{|c|}{ Soho's female } \\
\hline Benza $^{\mathrm{b}}$ & & 12.5 & $\dagger$ & 13 & $\dagger$ & 12.5 & (1) \\
\hline \multirow{2}{*}{\multicolumn{2}{|c|}{$\begin{array}{l}\mathrm{h}^{\prime} \text { for Napoleon's } \\
\text { unit } \\
\mathrm{h}^{\prime} \text { for Witte's unit }\end{array}$}} & \multicolumn{2}{|c|}{$\begin{array}{l}\mathrm{h}^{\prime}=0.964 ; P=0.010 \\
\mathrm{DC}=1.000\end{array}$} & \multicolumn{2}{|c|}{$\begin{array}{l}\mathrm{h}^{\prime}=0.946 ; P=0.006 \\
\mathrm{DC}=0.997\end{array}$} & \multicolumn{2}{|c|}{$\begin{array}{l}\mathrm{h}^{\prime}=1.000 ; P=0.007 \\
\mathrm{DC}=1.000\end{array}$} \\
\hline & & \multicolumn{2}{|c|}{$\mathrm{t} \mathrm{h}^{\prime}=1.000 ; P=0.247$} & \multicolumn{2}{|c|}{$\mathrm{h}^{\prime}=1.000 ; P=0.050$} & \multicolumn{2}{|c|}{$\mathrm{h}^{\prime}=0.768 ; P=0.140$} \\
\hline \multicolumn{2}{|c|}{$h^{\prime}$ for all females } & \multicolumn{2}{|c|}{$\begin{array}{l}\mathrm{h}^{\prime}=0.648 ; P=0.001 \\
\mathrm{DC}=0.952\end{array}$} & \multicolumn{2}{|c|}{$\begin{array}{l}\mathrm{h}^{\prime}=0.629 ; P=0.002 \\
\mathrm{DC}=0.985\end{array}$} & \multicolumn{2}{|c|}{$\begin{array}{l}\mathrm{h}^{\prime}=0.495 ; P=0.029 \\
\mathrm{DC}=1.000\end{array}$} \\
\hline
\end{tabular}

Dominance ranks are assigned based on spontaneous submissive acts between females. Dominance ranks within the separate OMUs are given between brackets. In order to determine the linearity within an OMU, the male leader was included to reach minimum group size of 5 animals in each, for each of the 3 observation periods. h', improved linearity index [de Vries, 1995]; DC, directional consistency index.

${ }^{\mathrm{a}}$ Latta is the daughter of Tiet.

${ }^{\mathrm{b}}$ Quaza, Renza and Benza are daughters of Zwart; other genealogical relationships are unknown.

${ }^{\dagger}$ Only when a female started cycling and a male had rather exclusive sexual access to her, could she be assigned to this male's OMU.

had free access to the entire enclosure, but preferred to stay outside as the weather allowed (on rainy, windy, or cold days they stayed inside most of the time).

\section{Observations}

Since observation conditions in the outside enclosure were much better than in the inside, the study was conducted during summer periods only (May-September). This resulted in a total of 82,93 , and 84 observation days (all occurrence observations) and $145.5,182.5$, and $252 \mathrm{hr}$ of focal animal sampling for 1996,1997 , and 1998, respectively.

Observations covered most of the active day, which ensured that most grooming bouts and agonistic interactions were observed. Focal-animal sampling data [Altmann, 1974] on the 13 females were collected in 30-min observation bouts distributed evenly throughout the day. Frequencies and duration of grooming bouts and frequencies of agonistic interactions by and towards the focal animal were scored. In the meantime all occurrence data [Altmann, 1974] were collected on the grooming and agonistic interactions of all the other animals. 


\section{0 / Leinfelder et al.}

\section{Grooming}

All grooming bouts were taken into account (reciprocated and nonreciprocated). Barrett et al. [1999] and Henzi and Barrett [1999] considered groom trading on a short-term scale and applied the biological market model to predict within-bout reciprocation. However, because of its tension- and stress-reducing effects [Boccia, 1987], we argue that grooming can also serve as a commodity to be traded on a long-term scale. This may be particularly true for captive groups in which conditions are much more crowded than in feral groups, and in which grooming can become an important tension-reduction strategy to cope with longlasting high-density conditions [Judge \& de Waal, 1997]. Hence, we decided to consider all grooming interactions over each of the three observation periods.

Grooming is an obvious behavior, and as a consequence data obtained by all occurrence sampling gave a reliable picture of the distribution of grooming frequencies. It was impossible to keep a record of the duration of all ongoing grooming bouts at a certain moment. Therefore, data on duration of grooming bouts were only collected by focal animal sampling. To prevent double counting we did not record all occurrence data involving the female that was the focus of a focal animal observation session at that moment. Both data sets of female grooming frequencies are significantly correlated for all of the three observation periods (1996: $\tau_{\mathrm{rw}}=0.635, P=0.001 ; 1997: \tau_{\mathrm{rw}}=0.659, P=0.0002 ; 1998: \tau_{\mathrm{rw}}=0.661, P=$ 0.001 ), justifying their pooling; this resulted in a more accurate and reliable representation of the distribution of female grooming frequencies than the one we got when only one of both datasets was considered.

Although data obtained by focal animal sampling on grooming frequency and grooming time were significantly correlated $\left(1996: \tau_{\mathrm{rw}}=0.893, P=0.001 ; 1997\right.$ : $\left.\tau_{\mathrm{rw}}=0.891, P=0.001 ; 1998: \tau_{\mathrm{rw}}=0.959, P=0.001\right)$, Dunbar [1992] indicated that animals are time constrained and consequently analyses of grooming data should be based on duration and not on frequency. However, the data set we obtained for grooming frequency (based on focal animal sampling and alloccurrence sampling) is much more elaborate, and hence more representative of the distribution of grooming interactions, than the data set on grooming time (based on focal animal sampling only). Therefore, we decided to use grooming frequency and grooming time (time spent grooming per hour) to analyze the distribution of grooming interactions in our study group.

According to Kummer's pilot study [1968] hamadryas females direct most of their grooming interactions towards the male leader of the OMU. Although data on hamadryas females in the wild are scarce, recent observations [Swedell, 1999] indicated that not all populations are characterized by the star-shaped sociogram, and that frequent association and grooming among females occur even across the unit boundaries. Therefore, we analyzed the grooming data for the entire study group. Grooming interactions within the OMUs were analyzed as well to examine whether the grooming distribution within the OMUs is similar to that among the females in the whole group.

\section{Dominance Hierarchy}

The female dominance hierarchy was based on the direction of spontaneous submissive acts. Each summer was considered as a separate period, since some rank reversals occurred. The improved linearity index $h^{\prime}$ (which is corrected for the number of unknown relationships) [de Vries, 1995] was significant for the three observation periods (Table II). That $h^{\prime}$ values were not very high was mainly 
Rank and Grooming in Hamadryas Baboons / 31

caused by the inclusion of the youngest females, which are rarely involved in adult conflicts, thereby increasing the number of unknown relationships (i.e., dyads in which no agonistic encounters have been observed). The values of the directional consistency (DC) index [Vervaecke et al., 2000], indicating the overall degree of unidirectionality within the dyads, were all very high (higher than 0.95 (see Table II)). According to de Vries [1998], ordering the individuals in a linear or near-linear hierarchy is worthwhile and justified whenever the linearity test yields a significant outcome. After minimization of the total number of inconsistencies and minimization of their total strength (i.e., the I and SI method) [de Vries, 1998] the females could be ranked into a linear hierarchy with rank number 1 assigned to the highest-ranking individual and rank number 13 to the lowest-ranking female (see Table II). Adjacently ranking females with unknown relationships were assigned mean ranks. Strictly considered, it was inappropriate to use this method for ranking the females in Witte's OMU in 1996 and 1998 because the significance level was not reached. However, since no intransitive triangular dominance relationships were present, and since the directional consistencies were high, we applied the I and SI method for this unit as well.

Based on this (near-) linear hierarchy, a rank matrix (in which cells of a column are filled with the rank number of the column individual) and a rank difference matrix (each cell represents the positive value of the difference between the rank number of the row and the column individual) were created.

Although kinship is known to have a confounding effect on dominance effects in female cercopithecines [e.g., Silk, 1982; Chapais, 1983], its impact on female hamadryas relationships is not yet known. Therefore, since the genealogy of the older colony members was unknown (although at least some of them should have been mother-daughter or sister pairs), known mother-daughter dyads were not excluded from the analysis.

\section{Statistical Methods}

Data on grooming and submissive interactions are summarized in social interaction matrices, in which rows and columns represent individuals. Data in such interaction matrices are statistically dependent and should be analyzed with special statistical procedures, such as the Kr-test [Hemelrijk, 1990a, b]. Matrix comparison by means of the rowwise $\mathrm{Kr}$-test takes the individual differences in capacities or tendencies into account, as correlations are only performed within every row ("individual") and combined over all rows. Kendall's rowwise matrix correlation coefficients $\left(\tau_{\mathrm{rw}}\right)$ and the corresponding probability values based on 10,000 random permutations were calculated by MatMan for Windows, a program for the analysis of sociometric matrices [de Vries et al., 1993; see also de Vries, 1993].

To determine whether grooming within dyads was directed up the hierarchy, a $t$-test for dependent samples was used.

To verify whether grooming increases with decreasing rank differences, we compared the rank distance matrix with the dually normalized symmetric grooming matrices (grooming frequency and grooming time). The symmetric grooming matrices (each cell represents the sum of the active contribution of both grooming partners) have been dually normalized by means of fitting homogeneous margins [Freeman et al., 1992].

To examine whether reciprocity in grooming increases with decreasing rank differences, we created an index for the reciprocity of grooming by applying the formula $R_{\mathrm{ij}}=2 \times \operatorname{Min}\left(\mathrm{X}_{\mathrm{ij}}, \mathrm{X}_{\mathrm{ji}}\right) /\left(\mathrm{X}_{\mathrm{ij}}+\mathrm{X}_{\mathrm{ji}}\right)$, in which $\mathrm{X}_{\mathrm{ij}}$ represents the number 


\section{2 / Leinfelder et al.}

(duration) of grooming interactions from individual $i$ to individual $j$ [cf., Seyfarth, 1980].

The contribution of low-ranking females to the amount of grooming (grooming frequency and grooming time) within a dyad was calculated by the formula $\mathrm{gm}_{\text {sub }} /\left(\mathrm{gm}_{\text {sub }}+\mathrm{gm}_{\mathrm{dom}}\right)$, in which $\mathrm{gm}_{\text {sub }}\left(\mathrm{gm}_{\mathrm{dom}}\right)$ indicates the grooming frequency/ time of the lowest ranking (highest ranking) female within the dyad.

As grooming did not occur in all dyads, the reciprocity index and the proportional contribution of the lowest-ranking female was undefined for some pairs of animals and the rowwise matrix correlation test could not be applied. Therefore, the possible relation between these parameters and the rank difference was examined by means of a Spearman rank correlation test. However, in small samples the reciprocity index and the proportional contribution can be easily skewed merely by chance. Therefore, pairs of animals in which less than four grooming interactions took place were excluded from the analysis.

We analyzed the data for the successive years separately because some rank reversals occurred. All tests were two-tailed.

\section{RESULTS}

At the Antwerp Zoo female dominance rank is not correlated with access to the male (in contrast with results for the same group when there was only one OMU [Vervaecke et al., 1992]), nor with access to food in general (measured by total feeding time, number of feeding bouts, and mean length of feeding bouts) (Deleu et al., unpublished results). The only rank-related advantage in our study group seems to be an improved access of dominant females to preferred food items when food is offered in one or two piles. Although food is offered clumped in space and time, it is supplied abundantly. Consequently, all animals obtain sufficient food. Nevertheless, increased aggression rates during food sessions indicate that contest competition over food occurs [Deleu, 1998]. The low frequency and the unidirectionality of aggressive interactions outside the food sessions indicate that dominance relationships are rather strict instead of relaxed [de Waal \& Lutrell, 1989]. The combination of a linear dominance hierarchy, rather strict dominance relationships, and the occurrence of contest competition suggests rankrelated access to limited resources and a potential to interchange grooming for rank-related benefits, such as access to preferred food, and thus that a preference to groom high-ranking females can arise.

Prediction 1. Female hamadryas baboons direct their grooming up the hierarchy. To check whether the distribution of grooming interactions was influenced by rank, a rowwise matrix correlation test was conducted comparing the rank matrices with the being-groomed matrices (based on grooming frequency and grooming time). The results (Table III, panel 1 upper part) indicate that rank did not predict frequency of, or time being groomed: females did not receive more grooming from low-ranking females than from high-ranking ones in any of the 3 years. Comparisons between the rank matrices and the grooming matrices for all females revealed significant negative correlations for grooming frequency in 2 out of 3 years (Table III, panel 1 lower part), indicating that females preferred to groom high-ranking females. However, for grooming time this preference was not found in any of the 3 years. Also, when analyzed for each OMU separately, grooming was not related to rank in any of the three observation periods (Table III, panel 1). In general, we can conclude that the influence of rank on the grooming distribution was very weak.

Due to competition (contest or outbidding competition) to get access to the 
TABLE III. Rowwise Matrix Correlation Tests (Kr-tests) Testing for the Attractiveness of High Ranking Grooming Partners, the Possible Effects of Competition, and Friendship

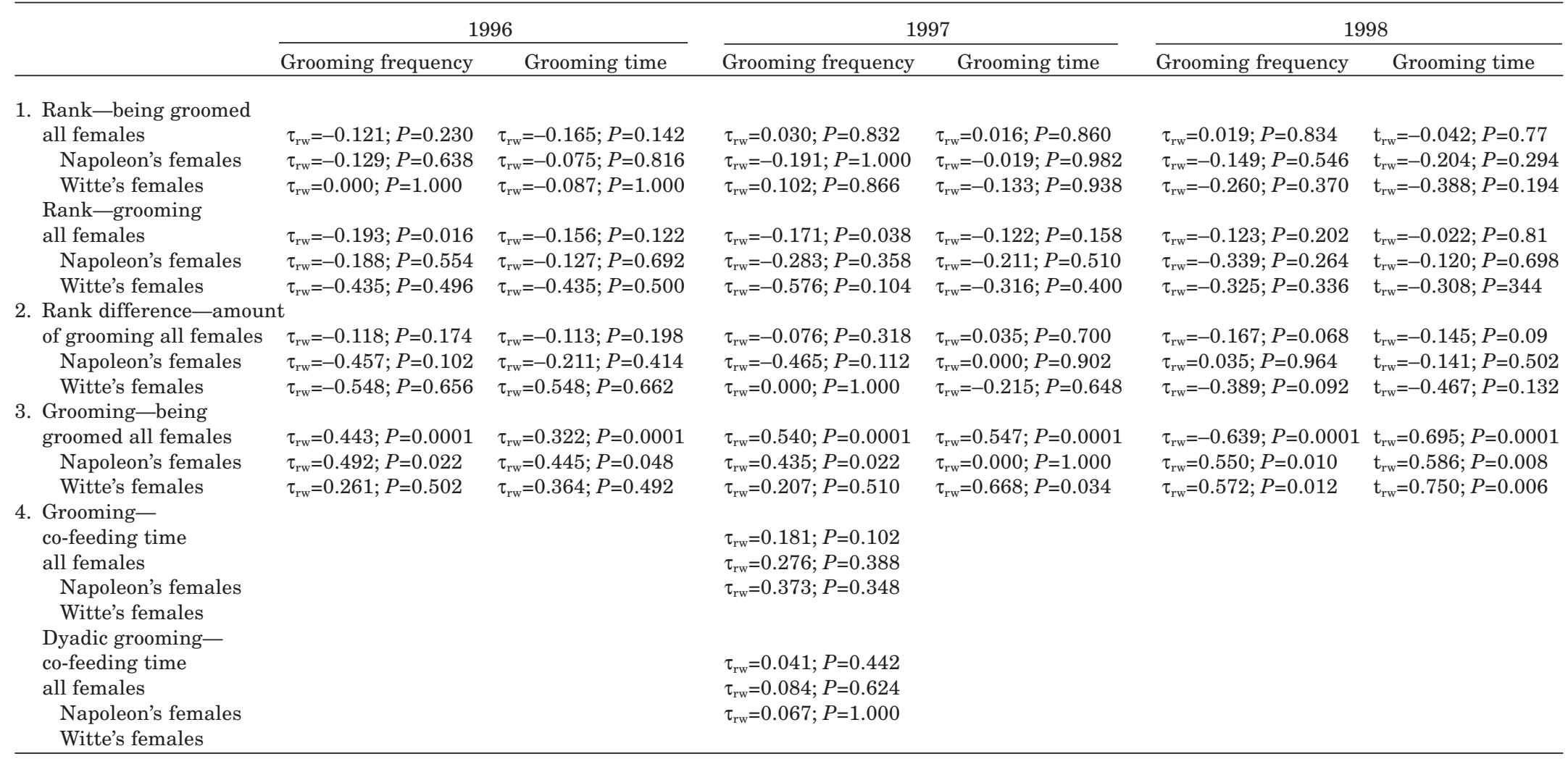

Correlation coefficients and probabilities are given for grooming frequency (and hourly grooming rates) for the entire group of females and for the separate units. Due to small sample sizes, within OMU results should be considered with caution. 


\section{4 / Leinfelder et al.}

preferred high-ranking grooming partners, the overall tendency to groom up the hierarchy could be confounded. However, on a dyadic level the tendency to groom up the hierarchy should be reflected in more grooming of the lower ranking animal to the higher ranking one than the other way around. None of the three observation periods revealed significant results within or between OMUs, except for the grooming frequency in 1998, in which the results confirmed the prediction (Table IV). In general, lower ranking females did not invest more in grooming relationships with higher ranking females than vice versa.

Prediction 2. Closely ranking females groom at higher rates than distantly ranking females. Preference for high-ranking grooming partners will result in (contest or outbidding) competition for access to them. As a consequence, grooming will be mainly taking place among closely ranking females. Comparison of the dually normalized symmetric grooming matrices with the rank difference matrices by means of a rowwise Kr-test revealed that in none of the 3 years grooming frequency and grooming time were correlated with rank differences (Table III, panel 2).

Prediction 3. Grooming is more reciprocal among closely ranking females than among distantly ranking ones. Closely ranking females have comparable access to preferred resources, making them equally attractive as grooming partners for each other. Therefore, they are expected to groom each other more reciprocally than distantly ranking females that have different access. The relation between rank differences and the indices for the reciprocity of grooming was investigated by means of a Spearman rank correlation test. Only in 1997 did females seem to groom each other more reciprocally (based on frequency) as rank distances decreased. Results of the other observation periods and results on grooming time pointed in the same direction, although the significance level was not reached. Results based on grooming time and frequency within the OMUs were less consistent, and only the 1998 grooming frequency within Napoleon's OMU confirmed the prediction significantly (Table V, panel 1).

Prediction 4. Low-ranking females contribute proportionally more to the grooming rates within distantly ranking dyads than in closely ranking dyads. The imbalance in access to limited resources is expected to be more pronounced in distantly ranking dyads. Hence, one-sided grooming interactions with the lowerranking female contributing proportionally more to the dyadic grooming frequency and grooming time are expected as rank distance increases. Spearman rank correlation tests indicated that this was not the case: rank distance does not seem to influence a female's proportional contribution to the dyadic grooming rates (Table V, panel 2).

All in all, none of the four predictions that are to be expected when possibility A (in Table I) holds were confirmed. This result surprised us, since dominance relationships are rather strict and dominant females have increased access to preferred food items (Deleu et al., unpublished results), which creates a potential for trading grooming for tolerance at the feeding site. However, rowwise matrix correlation tests comparing grooming with the time spent cofeeding during the first 5 min of feeding sessions in 1997 in which food was offered on one pile (Deleu et al., unpublished results) revealed no significant results. There were also no significant results when the time spent cofeeding was compared with the grooming efforts of the lower ranking females (Table III, panel 4, upper part), or with the combined grooming efforts of both dyad members (Table III, panel 4, lower part). The groom trade model presented in Table I specifies circumstances under which this potential to trade grooming for some rank-related commodity, e.g., tolerance at the food pile when preferred food is still available, is not ex- 
TABLE IV. t-test for Dependent Samples Testing Whether the Lowest Ranking or the Highest Ranking Animal Groomed Most

Grooming frequency

all females

Napoleon's females

Witte's females

Grooming time

all females

Napoleon's females

Witte's females

Only dyads in which at least 4 grooming interactions took place were considered.

$\mathrm{n}=36 ; \mathrm{t}=-0.151 ; P=0.088$

$\mathrm{n}=10 ; \mathrm{t}=1.006 ; P=0.340$

1998

$\mathrm{n}=42 ; \mathrm{t}=0.184 ; P=0.855$

$\mathrm{n}=12 ; \mathrm{t}=0.602 ; P=0.559$

$\mathrm{n}=10 ; \mathrm{t}=1.347 ; P=0.211$

$\mathrm{n}=38 ; \mathrm{t}=2.118 ; P=0.041$

$\mathrm{n}=11 ; \mathrm{t}=0.162 ; P=0.874$

$\mathrm{n}=8 ; \mathrm{t}=1.044 ; P=0.331$

$\mathrm{n}=21 ; \mathrm{t}=0.071 ; P=0.944$

$\mathrm{n}=10 ; \mathrm{t}=-0.312 ; P=0.762$

$\mathrm{n}=17 ; \mathrm{t}=0.283 ; P=0.78$

$\mathrm{n}=5 ; \mathrm{t}=0.521 ; P=0.630$ $\mathrm{n}=5 ; \mathrm{t}=-0.656 ; P=0.548$ $\mathrm{n}=16 ; \mathrm{t}=-0.148 ; P=0.682$ $\mathrm{n}=5 ; \mathrm{t}=-0.283 ; P=0.791$ 
TABLE V. Spearman Rank Correlation Tests, Testing Whether Reciprocity Increases With Decreasing Rank Differences, the Proportional Contribution of the Lowest Ranking Female Within a Dyad Increases With Increasing Rank Differences, and Reciprocity Increases With the Amount of Grooming Interactions

1996

1997

$\mathrm{n}=38 ; \mathrm{R}=-0.314 ; P=0.055$ $\mathrm{n}=10 ; \mathrm{R}=0.210 ; P=0.560$ $\mathrm{n}=6 ; \mathrm{R}=0.370 ; P=0.470$

$\mathrm{n}=16 ; \mathrm{R}=-0.293 ; P=0.27$ $\mathrm{n}=7 ; \mathrm{R}=0.501 ; P=0.252$ $\mathrm{n}=3 ; \mathrm{R}=0.000 ; P=1.000$

$\mathrm{n}=38 ; \mathrm{R}=0.037 ; P=0.825$ $\mathrm{n}=10 ; \mathrm{R}=-0.077 ; P=0.832$ $\mathrm{n}=6 ; \mathrm{R}=0.339 ; P=0.510$

$\mathrm{n}=16 ; \mathrm{R}=-0.526 ; P=0.036$ $\mathrm{n}=7 ; \mathrm{R}=-0.772 ; P=0.042$ $\mathrm{n}=3 ; \mathrm{R}=0.000 ; P=1.000$

$\mathrm{n}=48 ; \mathrm{R}=0.446 ; P=0.0015$ $\mathrm{n}=13 ; \mathrm{R}=0.406 ; P=0.168$ $\mathrm{n}=6 ; \mathrm{R}=0.319 ; P=0.538$

$\mathrm{n}=24 ; \mathrm{R}=0.424 ; P=0.039$ $\mathrm{n}=10 ; \mathrm{R}=0.031 ; P=0.933$ $\mathrm{n}=4 ; \mathrm{R}=0.949 ; P=0.051$ $\mathrm{n}=42 ; \mathrm{R}=0.444 ; P=0.003$ $\mathrm{n}=13 ; \mathrm{R}=-0.195 ; P=0.523$ $\mathrm{n}=10 ; \mathrm{R}=-0.398 ; P=0.254$

$\mathrm{n}=22 ; \mathrm{R}=-0.144 ; P=0.524$ $\mathrm{n}=11 ; \mathrm{R}=0.168 ; P=0.622$ $\mathrm{n}=5 ; \mathrm{R}=0.103 ; P=0.870$

$\mathrm{n}=42 ; \mathrm{R}=0.168 ; P=0.287$ $\mathrm{n}=13 ; \mathrm{R}=-0.119 ; P=0.523$ $\mathrm{n}=10 ; \mathrm{R}=0.201 ; P=0.578$

$\mathrm{n}=22 ; \mathrm{R}=0.072 ; P=0.750$ $\mathrm{n}=11 ; \mathrm{R}=-0.188 ; P=0.579$ $\mathrm{n}=5 ; \mathrm{R}=-0.359 ; P=0.553$

$\mathrm{n}=54 ; \mathrm{R}=0.639 ; P=0.0000$ $\mathrm{n}=15 ; \mathrm{R}=0.189 ; P=0.499$ $\mathrm{n}=10 ; \mathrm{R}=0.640 ; P=0.461$

$\mathrm{n}=30 ; \mathrm{R}=0.375 ; P=0.041$ $\mathrm{n}=12 ; \mathrm{R}=0.080 ; P=0.806$ $\mathrm{n}=9 ; \mathrm{R}=0.288 ; P=0.452$
1998

$\mathrm{n}=41 ; \mathrm{R}=-0.300 ; P=0.057$ $\mathrm{n}=11 ; \mathrm{R}=-0.722 ; P=0.012$ $\mathrm{n}=12 ; \mathrm{R}=0.384 ; P=0.218$

$\mathrm{n}=19 ; \mathrm{R}=-0.250 ; P=0.302$ $\mathrm{n}=5 ; \mathrm{R}=0.000 ; P=1.000$ $\mathrm{n}=8 ; \mathrm{R}=0.265 ; P=0.527$

$\mathrm{n}=41 ; \mathrm{R}=0.185 ; P=0.247$ $\mathrm{n}=11 ; \mathrm{R}=-0.090 ; P=0.792$ $\mathrm{n}=12 ; \mathrm{R}=-0.593 ; P=0.042$

$\mathrm{n}=19 ; \mathrm{R}=-0.250 ; P=0.302$ $\mathrm{n}=5 ; \mathrm{R}=-0.354 ; P=0.559$ $\mathrm{n}=8 ; \mathrm{R}=-0.441 ; P=0.274$

$\mathrm{n}=45 ; \mathrm{R}=0.631 ; P=0.0000$ $\mathrm{n}=13 ; \mathrm{R}=0.555 ; P=0.049$ $\mathrm{n}=12 ; \mathrm{R}=0.329 ; P=0.297$

$\mathrm{n}=25 ; \mathrm{R}=0.556 ; P=0.004$ $\mathrm{n}=8 ; \mathrm{R}=0.468 ; P=0.242$ $\mathrm{n}=9 ; \mathrm{R}=0.769 ; P=0.015$
Napoleon's females

Witte's females 
Rank and Grooming in Hamadryas Baboons / 37

pected to be realized and thus grooming is only exchanged for itself. In the next two paragraphs, predictions 5 and 6 related to this situation are tested.

Prediction 5. If grooming is a commodity that can only be traded for itself, grooming relationships are expected to be highly reciprocal regardless of rank differences. The matrices of grooming and the matrices of being groomed (i.e., the transposed grooming matrix) were compared by means of rowwise matrix correlation tests. For all females together these tests revealed highly significant correlations for all observation periods for female grooming frequency and grooming time (Table III, panel 3). The same was found, but was somewhat less significant, for the females in Napoleon's unit, except for the time spent grooming in 1997. In Witte's OMU grooming and being groomed were also positively correlated, but the significance level was only reached in one of three observation periods for grooming frequency, and in two observation periods for grooming time (Table III, panel 3). In general, females preferred to groom those by whom they are groomed most often. This was the case for every single female, except for Mekka, a hand-raised female that has never been groomed by other females (Table VI).

Prediction 6. If grooming is a commodity that can only be traded for itself, grooming relationships are expected to be more reciprocal among regularly grooming partners than among occasional groomers, since market forces will result in the survival of relationships with reliable partners only.

Spearman rank correlation tests, for dyads in which at least two grooming interactions occurred, indicated that the reciprocity index was significantly correlated with the amount of grooming within a dyad, for grooming time and frequency. Results within the separate OMUs were consistent with the prediction but did not reach significance in all cases (Table V, panel 3).

\section{DISCUSSION}

Based on the linearity and unidirectionality (strictness) of the dominance relationships in combination with the occurrence of food-related contest competi-

TABLE VI. Results of Rowwise Matrix Correlation Test for Frequencies of Grooming and Being Groomed (Kendall's $\tau$ is Undefined for the Hand-Reared Female Mekka, Since Other Adult Females Never Groom Her)

\begin{tabular}{lccc}
\hline & \multicolumn{3}{c}{ Kendall's $\tau$} \\
\cline { 2 - 4 } & 1996 & 1997 & 1998 \\
\hline Donna & 0.61 & 0.72 & 0.54 \\
Mekka & Undefined & Undefined & Undefined \\
Muis & 0.67 & 0.63 & 0.41 \\
Piggy & 0.46 & 0.80 & 0.73 \\
Pruts & 0.32 & 0.31 & 0.28 \\
Tiet & 0.62 & 0.52 & 0.72 \\
Flap & 0.71 & 0.80 & 0.75 \\
Hoofd & 0.56 & 0.14 & 0.65 \\
Lätta & -0.22 & 0.43 & 0.53 \\
Quaza & 0.07 & 0.62 & 0.82 \\
Renza & 0.62 & 0.67 & 0.82 \\
Zwat & 0.55 & 0.62 & 0.85 \\
Benza & 0.60 & 0.56 & 0.78 \\
$\tau_{\text {rw }}$ & 0.443 & 0.540 & 0.639 \\
$P$ & 0.0001 & 0.0001 & 0.0001 \\
\hline
\end{tabular}




\section{8 / Leinfelder et al.}

tion among the female hamadryas baboons at the Antwerp Zoo, the groom trade model predicts that a potential to interchange grooming for other rank-related benefits can arise and that dominance relationships will be reflected in the distribution of grooming interactions. However, our results show that in general there appears to be no or only a slight influence of dominance rank on the distribution of grooming interactions. Although some significant results were found, the correlations were so low that this conclusion seems to be justified. Results of the analyses performed for the two one-male units separately point in the same direction.

What could be the cause of this rather surprising result? It might be that dominance relationships were not a reliable predictor for the grooming pattern in this study because of the confounding effect of kinship. In most matrilineally organized species, closely related females occupy adjacent ranks (e.g., Cercopithecus aethiops [Cheney et al., 1981]; Macaca mulatta [Chapais, 1983]; Macaca radiata [Silk, 1982]; Papio anubis [Scott, 1984]; and Papio cynocephalus [Hausfater et al., 1982; Samuels et al., 1987]). At least for some of these the relation between dominance status and the distribution of grooming interactions seems to be mainly a consequence of kinship (e.g., Macaca radiata [Silk, 1982] and Macaca mulatta [Chapais, 1983]). Unfortunately, no studies have been done about the effect of kinship on the social relationships of female hamadryas baboons. Exclusion of the four known mother-daughter pairs from our analysis did not change the results with respect to the distribution of grooming interactions. As far as we can tell, based on the incomplete genealogy of the study group, kinship does not seem to have a clear-cut influence on the grooming pattern. This seems to be further confirmed by the considerable variation in the grooming relationships of the female Zwart with each of her three daughters.

Since the distribution of grooming interactions was not, or was only slightly, influenced by dominance rank and kinship, the question remains as to why females developed such highly differentiated grooming relationships. A possible explanation is that grooming is a valuable commodity in itself and females just groom to be groomed. Support for this pattern is common, even in despotic species: animals most often groom those by whom they are groomed most often (Papio hamadryas ursinus [Barrett et al., 1999; Henzi \& Barrett, 1999; Silk et al., 1999]; Pan troglodytes [Hemelrijk \& Ek, 1991]; Theropithecus gelada [Dunbar, 1983b]; Papio hamadryas hamadryas [Stammbach, 1978]; Erythrocebus patas [Muroyama, 1994; Nakagawa, 1992]). Our results seem to confirm this hypothesis as well. Significant and rather strong correlations were found for the three observation periods for the females in general and for Napoleon's OMU. Results in Witte's OMU were less convincing, probably because this OMU is growing every year and relationships with newly acquired females take some time to develop [Abegglen, 1984].

According to the groom trade model, the exchange of grooming for itself can be expected in three different circumstances (see Table I, panels B and C). The first is that the dominance relations are relaxed, the rank order is not steep, and there are (almost) no rank-related, marketable commodities. In our study group this was not the case, since the hamadryas females could be ranked in a linear hierarchy with clear-cut dominance relations; moreover, contest competition seemed to be important, indicating that there were rankrelated commodities. Other conditions for which grooming is not expected to be traded for some rank-related commodity are that the values of these commodities and grooming do not match, i.e., either the value of the commodity 
Rank and Grooming in Hamadryas Baboons / 39

(which should also not be splittable into smaller parts) is too high relative to the value of grooming or it is too low.

The rank-related commodity that potentially could be traded for grooming is tolerance at the food pile when preferred food items are available, and sharing of these items. However, observations during feeding sessions in 1997 indicate that grooming was not traded for tolerance at a clumped food resource. Although more detailed food experiments are required to reveal the trading value of preferred food items in relation to being groomed, it could be argued that the last possibility (i.e., the value is too low relative to the value of grooming) is more likely to explain the lack of interchange of grooming in this study group. First, although contest competition restricts low-ranking females in their access to preferred food, the abundance of the food supply in general and the good shape of all the animals indicate that there was enough food to choose from. Moreover, the search for preferred food items soon enlarges the diameter of the food pile, whereby food becomes accessible for more animals as soon as the amount of preferred food items decreases. Second, the advantages of being groomed can become very important in small enclosures, such as the one at the Antwerp Zoo. Since grooming induces the production of $\beta$-endorphins [Keverne et al., 1989] it has a relaxing and tension reducing effect [Boccia, 1987], and it can have a positive influence on density-related stress effects. Although no data are available on stress levels in this group, other studies indicated that long-term crowding resulted in increased allogrooming outside aggressive contexts to reduce tension in order to cope with increased densities (chimpanzees [Nieuwenhuijsen \& de Waal, 1982] and macaques [Novak et al., 1992; Judge \& de Waal, 1997]) and with the coinciding potential for aggression [Judge, 2000].

Although it is not certain how costly grooming is for the groomer, it surely is beneficial for the groomed [Dunbar, 1996]. Therefore, it can be argued that "good groomers" have a commodity of high value to offer at the market place and others will preferentially interact with them. Accordingly, this would result in competition to groom good groomers and, consequently, in highly reciprocal grooming relationships between regular groomers and less reciprocal grooming interactions among occasional groomers. Our results on the overall female grooming relationships confirm this prediction.

Hamadryas females' close grooming relationships seem to be built on mutual trust and loyalty, the two main characteristics of friendship. Although Stammbach [1978] already mentioned friendship, in addition to dominance, as an important determinant for prevalence in hamadryas females, our results indicate that under the long-term high-density conditions at the Antwerp Zoo, friendship can become the most important determinant for the distribution of grooming interactions.

\section{ACKNOWLEDGMENTS}

We thank all members of the Primate Research Group of Antwerp University, especially Hilde Vervaecke, for their helpful discussion and comments on the manuscript; the four anonymous reviewers for their constructive comments on earlier drafts of this manuscript; and the Royal Zoological Society of Antwerp for permission to conduct this study. The zookeepers of the Monkey Building are acknowledged for their collaboration. Iris Leinfelder was supported by a DehousseGrant from the University of Antwerp (RUCA) and the Royal Zoological Society of Antwerp in association with the University of Antwerp and the Flemish Ministry of Science. Rebekka Deleu was a research assistant for the Fund for Scientific Research (FWO), Flanders, Belgium. 


\section{0 / Leinfelder et al.}

\section{REFERENCES}

Abegglen J-J. 1984. On socialization in hamadryas baboons: a field study. London and Toronto: Associated University Presses. $207 \mathrm{p}$.

Altmann J. 1974. Observational study of behavior: sampling methods. Behaviour 49:227-267.

Altmann J. 1980. Baboon mothers and infants. Cambridge: Harvard University Press. 242 p.

Barrett L, Henzi SP, Weingrill T, Hill RA. 1999. Market forces predict grooming reciprocity in female baboons. Proc R Soc Lond B 266:665-670.

Barrett L, Henzi SP, Weingrill T, Lycett JE, Hill RA. 2000. Female baboons do not raise the stakes but they give as good as they get. Anim Behav 59:763-770.

Barrett L, Henzi SP. 2001. The utility of grooming in baboon troops. In: Noë R, van Hooff JARAM, editors. Economics in nature. Social dilemmas and biological markets. Cambridge University Press.

Barton R. 1985. Grooming site preferences in primates and their functional implications. Int J Primatol 6:519-532.

Boccia ML. 1987. The physiology of grooming: a test for the tension reduction hypothesis. Am J Primatol 12:330.

Boccia ML, Reite M, Laudenslager M. 1989. On the physiology of grooming in a pigtail macaque. Physiol Behav 45:667-670.

Carpenter CR. 1942. Sexual behavior of free-ranging rhesus monkeys (Macaca mulatta). J Comp Psychol 33:113-142.

Chapais B. 1983. Dominance, relatedness and the structure of female relationships in rhesus monkeys. In: Hinde RA, editor. Primate social relationships: an integrated approach. Oxford: Blackwell Scientific Publications. p 209-219.

Cheney DL, Lee PC, Seyfarth RM. 1981. Behavioral correlates of non-random mortality among free-ranging female vervet monkeys. Behav Ecol Sociobiol 9:153-161.

Cheney DL, Seyfarth RM. 1990. How monkeys see the world. Chicago: University of Chicago Press. 377 p.

Deleu R. 1998. Dominantiestructuur en monopoliseerbaarheid van gelimiteerde hulpbronnen bij adulte vrouwelijke mantelbavianen (Papio hamadryas hamadryas) in gevangenschap. Licentiaatsthesis, Universiteit Gent.

de Vries H. 1993. The rowwise correlation between two proximity matrices and the partial rowwise correlation. Psychometrika 58:53-69.

de Vries H, Netto WJ, Hanegraaf PLH. 1993. MatMan: a program for the analysis of sociometric matrices and behavioural

transition matrices. Behaviour 125:157175.

de Vries H. 1995. An improved test of linearity in dominance hierarchies containing unknown or tied relationships. Anim Behav 50:1375-1389.

de Vries H. 1998. Finding a dominance order most consistent with a linear hierarchy: a new procedure and review. Anim Behav 55:827-843.

de Waal FBM, van Roosmalen A. 1979. Reconciliation and consolation among chimpanzees. Behav Ecol Sociobiol 5:55-66.

de Waal FBM, Lutrell LM. 1989. Toward a comparative socioecology of the genus Macaca: different dominance styles in rhesus and stumptail monkeys. Am J Primatol 19:83-109.

Dunbar RIM. 1983a. Structure of gelada baboon reproductive units. III. The male's relationship with his females. Anim Behav 31:565-576.

Dunbar RIM. 1983b. Structure of gelada baboon reproductive units. II. Social relationships between reproductive females. Anim Behav 31:556-564.

Dunbar RIM. 1988. Primate social systems. London: Chapman \& Hall. 373 p.

Dunbar RIM. 1991. Functional significance of social grooming in primates. Folia Primatol 57:121-131.

Dunbar RIM. 1992. Time: a hidden constraint on the behavioural ecology of baboons. Behav Ecol Sociobiol 33:35-49.

Dunbar RIM. 1996. Grooming, gossip and the evolution of language. London: Faber \& Faber. $230 \mathrm{p}$

Evans S, Poole TB. 1984. Long-term changes and maintenance of the pair-bond in common marmosets, Callithrix jacchus jacchus. Folia Primatol 42:33-41.

Fairbanks LA. 1980. Relationships among adult females in captive vervet monkeys: testing a model of rank-related attractiveness. Anim Behav 28:853-859.

Freeman LC, Freeman SC, Romney K. 1992. The implications of social structure for dominance hierarchies in red deer, Cervus elaphus L. Anim Behav 44:239-245.

Goosen C. 1981. On the function of allogrooming in Old World monkeys. In: Chiarelli AB, Corruccini RS, editors. Primate behaviour and sociobiology. Berlin: Springer. p 110-120.

Goosen C. 1987. Social grooming in primates. In: Liss AR, editor. Comparative primate biology. Vol. 2, part B. Behavior, cognition and motivation. New York: Alan R. Liss, Inc. p 107-131.

Hausfater G, Altmann J, Altmann S. 1982. Long-term consistency of dominance rela- 


\section{Rank and Grooming in Hamadryas Baboons / 41}

tions among female baboons (Papio cynocephalus). Science 217:752-755.

Hemelrijk CK. 1990a. A matrix partial correlation test used in investigations of reciprocity and other social interaction patterns at group level. J Theor Biol 143:405-420.

Hemelrijk CK. 1990b. Models of, and tests for, reciprocity, unidirectionality and other social interaction patterns at a group level. Anim Behav 39:1013-1029.

Hemelrijk CK, Ek A. 1991. Reciprocity and interchange of grooming and "support" in captive chimpanzees. Anim Behav 41:923935.

Henzi SP, Barrett L. 1999. The value of grooming to female primates. Primates 40:47-59.

Judge PG, de Waal FBM. 1997. Rhesus monkey behaviour under diverse population densities: coping with long-term crowding. Anim Behav 54:643-662.

Judge PG. 2000. Coping with crowded conditions. In: Aureli F, de Waal FBM, editors. Natural conflict resolution. Berkeley: University of California Press. p 129-154.

Keverne EB, Martensz N, Tuite B. 1989. Beta-endorphin concentrations in cerebrospinal fluid of monkeys are influenced by grooming relationships. Psychoneuroendocrinology 14:155-161.

Kummer H. 1968. Social organisation of hamadryas baboons. Basel: Karger. 189 p.

Kummer H. 1990. The social system of hamadryas baboons and its presumable evolution. In: de Mello M, White A, Byrne RW, editors. Baboons (XII Congress of the International Primatological Society, Brasilia, 1988). Brasilia. p 43-60.

Kurland JA. 1977. Kin selection in the Japanese monkey. Contrib Primatol 12:1-145.

Marler P. 1965. Communication in monkeys and apes. In: DeVore I, editor. Primate behavior. New York: Holt, Rinehart \& Winston. p 544-584.

Melnick DJ, Pearl MC. 1987. Cercopithecines in multimale groups: genetic diversity and population structure. In: Smuts BB, Cheney DL, Seyfarth RM, Wrangham RW, Struhsaker TT, editors. Primate societies. Chicago: University of Chicago Press. p 121-134.

Missakian EA. 1974. Mother-offspring grooming relations in rhesus monkeys. Arch Sex Behav 3:135-141.

Muroyama Y. 1994. Exchange of grooming for allomothering in female patas monkeys. Behaviour 118:103-119.

Nakagawa N. 1992. Distribution of affiliative behaviors among adult females within a group of wild patas monkeys in a nonmating, nonbirth season. Int J Primatol 13:73-96.
Nieuwenhuijsen K, de Waal FBM. 1982. Effects of spatial crowding on social behavior in a chimpanzee colony. Zoo Biol 1:5-28.

Noë R, Hammerstein P. 1995. Biological markets. Tree 10:336-339.

Novak MA, O’Neill P, Suomi SJ. 1992. Adjustments and adaptations to indoor and outdoor environments: continuity and change in young adult rhesus monkeys. Am J Primatol 28:125-138.

Sade DS. 1965. Some aspects of parent-offspring and sibling relations in a group of rhesus monkeys, with a discussion of grooming. Am J Phys Anthropol 23:1-18.

Sade DS. 1972. Sociometrics of Macaca mulatta. Linkages and cliques in grooming matrices. Folia Primatol 18:196-223.

Samuels A, Silk JB, Altmann J. 1987. Continuity and change in dominance relations among female baboons. Anim Behav 35:785793.

Schino G, Scucchi S, Maestripieri D, Turillazzi PG. 1988. Allogrooming as a tension-reduction mechanism: a behavioral approach. Am J Primatol 16:43-50.

Scott LM. 1984. Reproductive behavior of adolescent female baboons (Papio anubis) in Kenya. In: Small MF, editor. Female primates: studies by woman primatologists. New York: Alan R. Liss. p 77-100.

Seyfarth RM. 1977. A model of social grooming among adult female monkeys. J Theor Biol 65:671-698.

Seyfarth RM. 1980. The distribution of grooming and related behaviour among adult female vervet monkeys. Anim Behav 28:798-813.

Seyfarth RM, Cheney DL. 1984. Grooming, alliances and reciprocal altruism in vervet monkeys. Nature 308:541-543.

Seyfarth RM, Cheney DL. 1988. Empirical tests of reciprocity theory: problems in assessment. Ethol Sociobiol 9:181-188.

Silk JB. 1982. Altruism among female Macaca radiata: explanations and analysis of patterns of grooming and coalition formation. Behaviour 79:162-188.

Silk JB, Seyfarth RM, Cheney DL. 1999. The structure of social relationships among female savanna baboons in Moremi Reserve, Botswana. Behaviour 136:679-703.

Stammbach E. 1978. On social differentiation in groups of captive female hamadryas baboons. Behaviour 67:322-338.

Swedell L. 1999. Female friendships in a non-female-bonded species: social relationships between females in wild hamadryas baboons, Papio hamadryas hamadryas. Am J Primatol 49:106-107.

Trivers RL. 1971. The evolution of reciprocal altruism. Q Rev Biol 46:35-57.

Vervaecke H, Dunbar R, Van Elsacker L, Verheyen R. 1992. Interactions with and 


\section{2 / Leinfelder et al.}

spacial proximity to the males in relation Vervaecke $\mathrm{H}$, de Vries $\mathrm{H}$, van Elsacker L. to rank of captive female adult hamadr- 2000. Dominance and its behavioral meayas baboons (Papio hamadryas). Acta Zool sures in a captive group of bonobos (Pan Pathol Antver 92:61-77. paniscus). Int J Primatol 21:47-68. 